\title{
Integrated medicine in the management of chronic illness: a qualitative study
}

Sarah B Brien, Felicity L Bishop, Kirsty Riggs, David Stevenson, Victoria Freire and George Lewith

\begin{abstract}
Background

Complementary and alternative medicine (CAM) is popular with patients, yet how patients use CAM in relation to orthodox medicine (OM) is poorly understood.

\section{Aim}

To explore how patients integrate CAM and OM when self-managing chronic illness.

\section{Design of study}

Qualitative analysis of interviews.

Method

Semi-structured interviews were conducted with individuals attending private CAM practices in the UK, who had had a chronic benign condition for 12 months and were using CAM alongside OM for more than 3 months. Patients were selected to create a maximum variation sample. The interviews were analysed using framework analysis.

Results

Thirty five patient interviews were conducted and seven categories of use were identified: using CAM to facilitate OM use; using OM to support long-term CAM use; using CAM to reduce OM; using CAM to avoid $\mathrm{OM}$; using CAM to replace $\mathrm{OM}$; maximising relief using both CAM and OM; and returning to OM. Participants described initiating CAM use following a perceived lack of suitable orthodox treatment. Participants rejecting $\mathrm{OM}$ for a specific condition never totally rejected OM in favour of CAM.

Conclusion

Patients utilise CAM and OM in identifiably different ways, individualising and integrating both approaches to manage their chronic conditions. To support patients and prevent potential adverse interactions, open dialogue between patients, OM practitioners, and CAM practitioners must be improved.
\end{abstract}

Keywords

complementary medicine; chronic disease; qualitative.

\section{INTRODUCTION}

Complementary and alternative medicine (CAM) use is common in individuals with chronic health problems; $70-90 \%{ }^{1}$ of patients with arthritis and $50 \%$ with irritable bowel syndrome ${ }^{2}$ use CAM. Push and pull factors explain this phenomenon. Push factors include the perceived failure ${ }^{3}$ and adverse effects of orthodox medicine (OM), ${ }^{3,4}$ and dissatisfaction with its reliance on technology. ${ }^{5}$ Pull factors include the perceived effectiveness of $\mathrm{CAM}^{3,6-8}$ and belief that CAM offers a holistic ${ }^{3,8,9}$ and patient-centred approach. ${ }^{3,10}$

The majority of patients who use CAM integrate its use with $\mathrm{OM},{ }^{8,11}$ but we know little about how patients manage chronic conditions when using both approaches. Recent data suggest that people use and integrate CAM in different ways, as an alternative to $\mathrm{OM}$, as a supplement to OM, or as a non-medical treat. ${ }^{12}$ Some studies have found CAM users are less adherent to prescribed $\mathrm{OM},{ }^{4,13}$ while others identified no such effect. ${ }^{14-17}$ No studies have specifically investigated how individuals use CAM and OM

SB Brien, BSc, MSc, PhD, senior research fellow, Faculty of Health Sciences; FL Bishop, MA, MSc, PhD, CPsychol, Arthritis Research UK career development fellow; G Lewith, MD, FRCP, $M R C G P$, professor of health research, Department of Primary Care, Faculty of Medicine, University of Southampton, Southampton. K Riggs, BM, GP trainee ST1, Wessex Deanery, Otterbourne. D Stevenson, BM foundation year 2 doctor, St Mary's Hospital, Newport. V Freire, BSc, BM foundation year 1 doctor, Basingstoke and North Hampshire Hospital, Basingstoke.

Address for correspondence

Dr Sarah B Brien, Faculty of Health Sciences, Room 4005, Building 47, University Road, University of Southampton, Southampton, Hants S017 1BJ.

E-mail: s.brien@southampton.ac.uk

Submitted: 25 March 2010; Editor's response: 4 May 2010; final acceptance: 20 May 2010.

(CBritish Journal of General Practice

This is the full-length article (published online 31 Jan 2011) of an abridged version published in print. Cite this article as: Br J Gen Pract 2010; DOI: 10.3399/bjgp11X556254. 
together, and the impact this may have. Given the widespread use of CAM in the UK, ${ }^{18}$ potential safety issues, for example, drug-herb interaction ${ }^{19}$ and the low rates of disclosure of CAM use to medical practitioners, ${ }^{20}$ understanding this phenomenon is important. Therefore this qualitative study was conducted to identify how individuals with chronic illness use CAM and OM in relation to each other.

\section{METHOD}

\section{Data collection}

The study involved face-to-face, semi-structured interviews with patients who attended CAM practitioners in the UK (October 2006 to March 2009). CAM was defined using the National Center for Complementary and Alternative Medicine definition, ${ }^{21}$ and participants attending practitioner-based therapies (over-the-counter medication was also described and analysed) in the south of England were interviewed. Participants were recruited from 20 practitioners within 11 UK clinics; nine were sole practitioners, the remainder worked within a practice. All CAM practitioners (medically and non-medically trained) worked in the private sector and provided at least one of: acupuncture, nutritional medicine, homeopathy, and herbal medicine (all nonmanipulative CAMs only; osteopathy and chiropractice were excluded as these are considered mainstream and not complementary therapies). ${ }^{12}$ Inclusion criteria were: a medical diagnosis for at least 12 months with a non-terminal chronic condition, having been prescribed (but not necessarily taken) $\mathrm{OM}$, and experiencing at least two CAM consultations over 3 months. Participants were selected to constitute a maximum variation sample based on: sex; use of practitioner-based CAM therapy; and consulting medical and non-medically trained CAM practitioners. Recruitment ceased when thematic saturation was reached and no new ways of using $\mathrm{CAM} / \mathrm{OM}$ together could be identified.

Interviews were conducted in the participants' homes, lasted 30-90 minutes, and were audiorecorded and transcribed verbatim using pseudonyms to preserve anonymity. A topic guide, developed from the literature, was used flexibly; relevant issues raised by participants were explored in subsequent interviews. Open-ended questions probed participants' previous and current use of CAM and OM (Box 1).

\section{Data analysis}

All authors analysed the data using an inductive version of the framework approach, a structured methodology following five distinct but interconnected stages. ${ }^{22}$ Emerging themes were verified against the original transcripts. Meetings

\section{How this fits in}

Patients with chronic conditions are frequent users of complementary and alternative medicine (CAM) but little is understood about how patients integrate conventional medicine and CAM in the management of chronic illness.

Communication between patients and doctors about CAM use is often poor.

This study describes, for the first time, seven ways in which people with chronic medical conditions integrate CAM and conventional medicine. Patients using CAM do not stop using conventional medicine totally. The ways patients integrate these two systems are dynamic and changeable, and appear to be influenced by informed discussion with clinicians.

between authors ensured a reflexive approach during data analysis and interpretation to manage this potential source of bias; emerging themes and the subsequent conceptual model were reviewed and revised by the team. This iterative process was aided by discussion and reflective feedback to identify biases, overstatements, and discrepancies in the analytical and interpretative phases, ensuring the final model was fully supported by the data.

\section{RESULTS}

Seventy-seven individuals volunteered to participate, 41 were eligible and 35 were selected; 27 were women. Participants were between 20 and 88 years, all were white. The majority were highly educated (for example, architect and teacher) and most self-funded their treatment, although three received health insurance support and six had experienced some CAM within the NHS. Participants had a range of chronic conditions (chronic fatigue syndrome, multiple sclerosis, musculoskeletal disorders, and eczema) lasting between 1 and 58 years, with many having conditions that had persisted for at least 10 years.

All participants had used either homeopathy or acupuncture and some form of nutritional medicine

Box 1. Examples of questions from interview guide.

- Can you tell me a little bit about your condition?

- Can you tell me what medications your GP or consultant has prescribed?

- What do you think about taking conventional medicines?

- Can you tell me a little about when you started using complementary medicine, for this illness and why this was?

- Have you ever spoken to your GP/hospital doctor about your use of complementary medicine?

- Have you ever spoken to your complementary medical practitioner about your conventional medicine use?

- Do you think your complementary medicine use has changed how you view your conventional medicine? 
Figure 1. The management of chronic ill health; balancing CAM and OM healthcare systems. (supplements or diet changes) in their CAM treatment. Participants had previously visited other CAM practitioners and used herbal medicines, traditional Chinese medicine, reflexology, Alexander technique, osteopathy and chiropractic manipulation, massage, Reiki, and kinesiology, all of which were discussed during the interviews and included in the analysis. Participants also discussed non-pharmaceutical interventions from their $\mathrm{OM}$ provided, for example, physiotherapy in addition to their experience of OM medication.

\section{The integration of OM and CAM in the management of chronic ill health}

Seven themes or ways of using CAM and OM were identified, which were related to participants' experiences with and beliefs about OM and CAM (Figure 1). They are described with illustrative quotes. Participants' names have been changed in the illustrative quotes to protect their anonymity.

\section{Facilitating use: using CAM to maintain OM use} CAM was used explicitly to counteract the sideeffects of $\mathrm{OM}$, enabling participants to continue using OM. Facilitating use appeared to occur when participants either experienced or worried about OM

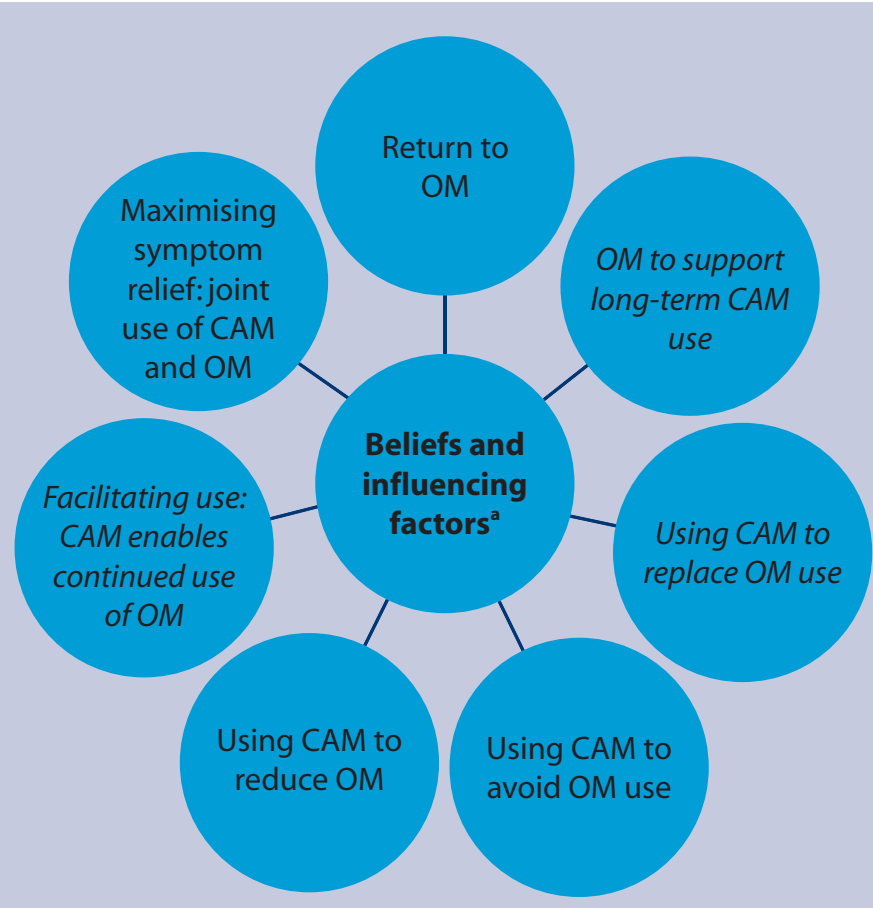

Italics indicate that this type of use was first identified in stage 1 of data collection and analysis. ${ }^{a} B e l i e f s$ and influencing factors include: beliefs about treatment, practitioner, and therapy; philosophy of healthcare system; in/effectiveness of complementary and alternative medicine (CAM) and orthodox medicine (OM); side effects of OM; seriousness of medical condition; practitioner's knowledge and qualifications; personal treatment preference; availability of healthcare system; cost; gaining control from treatment; previous experience of CAM; medical or CAM practitioners recommendations; desperation. side-effects but believed OM to be effective. The quotations from Amy and Sophie show how participants were unable or did not want to stop using OM because it was effective, despite its adverse sideeffects. CAM helped them manage these adverse reactions:

'I think the anaesthetic, I mean obviously it's a poison so I take, it made me very, very depressed it just really, I thought life just wasn't worth living and I thought for the sake of having the finger done, so I tried everything that I could recall that helped with depression and so in the end I just phoned [homeopath] up and said "what can I take? I'm at you know desperation point", she said "have you tried Aurum" [a homeopathic remedy] which is gold and er one drop I was up out of my depression and I was fine.' (Amy)

'And I think, primarily, latterly, he [CAM practitioner] has been, um, aware that the only way he can help me is to help me get over the effects of the antibiotics, as much as possible, to counteract the bad effects.' (Sophie)

\section{Using OM to supplement long-term CAM use}

This theme reflects the long-term use of CAM either to maintain health or wellbeing or to attempt to cure a condition, with OM being used for additional symptom control. Joseph managed his diarrhoea with CAM but used OM as his 'panic pill':

'I take that [CAM treatment] all the time and I top that up with Imodium ${ }^{\circledR}$ [loperamide] when I think that I might have a difficult day.' (Joseph)

Participants who faced taking medication for life wanted alternative options which they hoped would treat the cause of their symptoms. Fiona, for example, was typical of this style of integration, describing how she used CAM to try and treat the underlying cause of her irritable bowel:

'I mean in my particular case with the irritable bowel I think it [her orthodox treatment] is just curing the symptoms, I don't think it really helps.'

And later in the interview:

'I didn't really like the idea of going to the doctors and them saying it's something you're going to have to learn to live with and you are going to be on these tablets forever, I just thought I don't want that, l'd rather find out what's causing it and see if I can actually treat the cause and get rid of it completely.' (Fiona) 
They perceived CAM as holistic, individualised treatments that emphasise the causes of illness, while OM was considered as effective symptom relief but not curative. Harriet preferred to use CAM but worked as a performer, so often used OM to clear the seborrhoeic eczema on her face:

I would avoid antibiotics and hydrocortisone all the time if I could ... recently I, I put a little tiny sliver of hydrocortisone round my nose, cos I had something coming up, I think it was a gig or something.' (Harriet)

The defining characteristic of this theme is continued but variable use of OM for symptom relief. Some participants (Victoria) described how their need for symptomatic relief decreased because of their CAM treatment or an improved ability to cope with their health problems. This unexpected benefit of reducing OM was not the primary motivation for these participants using CAM:

'And you can cope better, so yeah, think, that's the big difference, is that, yes now I don't feel, unless it's absolutely necessary that I have to take a pain relief tablet.' (Victoria)

\section{Using CAM to reduce OM use}

Participants saw their OM intake as problematic because of associated side-effects, viewing CAM as potentially effective and as a means to reduce their OM intake. These participants still considered OM to be effective, using it for exacerbations of symptoms (as in the previous section, 'Using OM to supplement long-term CAM use'). Michael explained how he had managed to reduce his OM to the minimal dose, thus curtailing side-effects:

'Yeah well it's [CAM] allowed me to reduce the amount of OM. I mean, the [orthodox] tablets that I still have to take, I'm on, really, the lowest dose that I can take, whereas before I would have been on a higher dose and additional medications, like Imodium $^{\circledast}$ [loperamide].' (Michael)

And Denise explained how she had reduced her asthma inhaler after receiving homeopathic treatment

I know I went from using my asthma inhaler between four and eight times a day, depending really on the time of year, to less than once a month.' (Denise)

\section{Using CAM to avoid OM}

Participants using CAM to avoid OM, like Paul, described CAM as a more desirable form of treatment and wanted to stop, not just reduce, OM:

'If the disc comes out and it's out for a period of time, the muscles around it inflame and it gets a lot worse, but if she [CAM practitioner] can keep them coming back in again, it hasn't got time to become inflamed. Therefore things are a lot easier and this is where it keeps me off the drugs. Because if I hadn't gone to see her [CAM practitioner], I would still be popping tablets.' (Paul)

They were concerned about avoiding adverse effects, such as Joseph who was concerned about addiction to $\mathrm{OM}$ :

'If you have a chronic condition that, for which there is no cure, you may have to um, continue with medicine, but you don't want it to be um, OM because of all the, you know, all the, all the sideeffects, and the fear that it could be doing other things, that maybe, they may be toxic or they may be harmful in some way [...] I do feel that, uh, homeopathic medicines are more likely to be appropriate for chronic conditions.' (Joseph)

Natasha, however, avoided OM as she believed her illness was not serious enough to justify her OM treatment. This emphasises that patients' interpretations of illness, as well as beliefs about treatment, contribute significantly to their treatment decisions:

I've always felt a fraud getting these out, just never felt right, I mean if you are not well and you have something, that's fine, but l've never felt that acne is something like a real disease, although it is, and there are many people you know, it really does affect your life, and I know that for a fact, personally, but it's not a life-threatening thing [...] I just do feel that it [the NHS] is abused, and if I can do a little bit not to abuse it, and take from it [...] if I'm ill, there's the NHS, I will use it. I will go, um, and uh, but if there's something more minor, like if this flares up again, I would be inclined to try the homeopathic way, rather than burden an already burdened institution.' (Natasha)

Similarities were noted between using CAM to avoid $\mathrm{OM}$ use and using CAM to reduce OM use. Participants did not totally reject OM but avoided specific treatments for particular conditions when they became more convinced of using CAM, thus moving from using CAM to reduce OM to using CAM to avoid OM. Despite trying to avoid OM, use of OM investigations was almost always retained, as participants did not rely on CAM for diagnosis. 


\section{Using CAM to replace OM}

This theme describes participants using CAM as a sole intervention for a specific illness for which they perceived CAM to be effective, while continuing OM use for other problems. Patricia only used CAM for her migraines but $\mathrm{OM}$ for other conditions:

'No, they're separate [CAM and OM]. Anything wrong with my head, immediately complementary. I wouldn't dream of going to the doctor.' (Patricia)

Jessica, Kelly, and Doug turned to CAM after trying ineffective OM for their conditions:

'I think that really, um, the motivation for going for the complementary medicine was because of the failure of [orthodox] medicines to work for me.' (Jessica)

'I think probably I felt l'd exhausted what I could get from my GP. So I think I exhausted that avenue first and knew really that ... I knew what was on offer and I knew that, really, what was on offer was good up to a point, but I suppose I felt wasn't really helping me in the way that I felt I needed help.' (Kelly)

'They say I should go and see a physiotherapist and I'm sorry, the physiotherapist doesn't do anything for me ... 'cause [the acupuncturist] puts these ... electrodes on the back as well. The physiotherapist just wants me to do exercise and that just makes it worse. So I find that the acupuncture works much better.' (Doug)

Laura and Charlotte began using CAM to replace OM after experiencing OM side-effects:

'I mean it's a fairly widely known fact that homeopathic medicines don't have side-effects. Um, so I suppose that's a good thing. I wouldn't have any qualms about taking them, because they don't have, they don't have known side-effects.' (Laura)

'I mean I would never take conventional medicines without first finding out as much as I possibly can about what it is I'm taking, and the side-effects and all those sorts of stuff, um. And I would only take it if I really had to, you know, antibiotics or whatever, you know, if it was really necessary then I'm fine, and then l'd take it you know, and then l'd just not fight it anymore, but l'd want to be sure there wasn't a better alternative, I suppose [...] a more natural alternative perhaps.' (Charlotte)
Ryan decided to use CAM exclusively after having concerns about developing a tolerance to long-term OM use:

'I just didn't want to be relying on drugs, I didn't want my life dictated by a bottle of tablets.' (Ryan)

One participant, Iris, used CAM as a sole treatment in an attempt to determine its effectiveness:

'No, I stopped, actually, because I thought there's no point in taking those if I'm going to have acupuncture. I want to find out if it's working.' (Iris)

\section{Maximising symptom relief: joint use of CAM and $O M$}

In this context, CAM and OM were used together to maximise symptom relief. For participants using CAM and $\mathrm{OM}$ in this pragmatic fashion, effectiveness was not specific to either healthcare system. Sandra had so much joint pain she would use anything that might be effective:

'I think it was a combination of everything and ... to be perfectly honest, I didn't really care. Whatever helped in whatever way and in whatever combination, if it helped, that was what I stuck with. So I did, I had [CAM practitioner], I went to see [CAM practitioner] weekly in the beginning, and then ... and took all the [orthodox] medication at the same time.' (Sandra)

Vera also demonstrated this pragmatic approach to maximising symptom relief for her arthritis of the spine; using one form of health care at one point, and switching to the other type the next:

'I don't think I use the paracetamol or conventional medicines in any different ways before I went to alternative but I use them [CAM treatment] as well as but I don't use more or less, I just use them if I find I need to have it for pain until I can get a relief from conventional medicine at the moment.' (Vera)

\section{Returning to OM}

If CAM was ineffective, then participants rejected it and returned to using $\mathrm{OM}$ alone for that condition. For some, such as Amy, this was irrevocable and she was clear that she would not use CAM again for her condition:

'[The homeopath] sat with me and had bought out several remedies; I couldn't move from the car and try remedies for over about an hour and not one of them worked.' 
And then later explained how she returned to OM:

I came home and took Voltaro ${ }^{\circledR}$ [diclofenac], one of [my husband's], naughty really, one of [husband's] Voltarol ${ }^{\circledR}$, and I was just, I was knocked out for about ... three-quarters of a day, I would say and just slept and when I woke up I just had a feeling of tenderness in the area, but no pain the pain had gone and I didn't get it back.' (Amy)

Participants, like Louise, also returned to OM when they perceived CAM had cured their condition, and residual symptoms could be managed with $\mathrm{OM}$ :

'No, no, l've stopped now. I can't remember the reason why I stopped. I suppose I must have felt I was cured enough to cope with it ... if there are days when I think it's particularly bad, um, I go back to the conventional Imodium ${ }^{\circledR}$ [loperamide].' (Louise)

\section{Beliefs and experiences shaping CAM and OM use in chronic conditions}

Seven distinct ways of using CAM and OM were identified, and these were neither mutually exclusive nor static. The process of integrative care was dynamic and both condition and person dependent. Some participants only described one style, some reported changing CAM and OM use over time, and some used CAM and OM in multiple ways at the same time (often for different illnesses). Changes in participants' behaviour over time related to their treatment experiences, which either reinforced existing beliefs or inspired new beliefs. New beliefs could trigger a therapeutic re-evaluation, with participants starting to manage their care differently. Some beliefs were more important in shaping behaviour than others: for Dorothy and Tom, the perceived seriousness of their medical condition would always influence them to seek OM advice initially despite describing a clear preference for CAM:

I think I would try the complementary medicine first and if that doesn't work I then go to my GP, unless it was something serious and then l'd go to the GP first, obviously, but if it was something that I thought complementary medicine could sort, then l'd try that first.' (Dorothy)

'We would tend to try and use natural remedies or just work our way through it. But anything serious, then obviously, if you need antibiotics or things like that, you have to go to your doctor to get those.' (Tom)

Factors that informed participants' beliefs and appeared to shape the way they managed their health through integrating OM/CAM are listed in Figure 1. Most have been described in the study sample and also previously identified. However, practical issues, such as convenience and cost also influenced participants' behaviour, as did discussion with their clinicians. For example, Ryan preferred to use homeopathy but when his arthritic pain prevented him accessing homeopathic remedies he switched to orthodox painkillers:

'I get periods when I forget to take the [homeopathic remedy], or I run out and that's the situation now, I'm out of it, so I take paracetamol.' (Ryan)

CAM use could also be curtailed because of its cost despite a preference for CAM:

'Although I'm very much a believer in homeopathic and alternative medicine um, I will try OM if I think it might work, and if I think it might work without any expense.' (Joseph)

\section{DISCUSSION}

\section{Summary of main findings}

This is the first study to identify how individuals with a broad range of chronic benign conditions integrate CAM and OM, balancing the positive and negative aspects of each healthcare system thus creating an individualised approach enabling them to self-manage. The study identified seven different ways in which participants achieved this balance, describing how their CAM/OM use evolved as their beliefs changed and they experienced managing their illnesses with multiple treatments. Some participants reported switching between CAM and OM (and vice versa) because of lack of effectiveness, adverse side-effects, and delay in obtaining symptom relief or cost. Others also described the changing nature of decisions over time based upon their demands and experiences of CAM treatment. ${ }^{6,23-27}$

\section{Strengths and limitations of the study}

There are limitations to the study. The need for a conventional diagnoses and prescriptions for inclusion may have biased recruitment, as some people turn to CAM when their illness is not recognised, diagnosed, or amenable to OM. Some specific themes may have been identified because participants were recruited from private CAM rather than NHS clinics. However, participants did report experiences of ineffectual CAM treatments; consequently, this is unlikely to have confounded the analysis. These limitations are mitigated by a number of strengths. Saturation was reached and the population investigated reflects the 
demography of typical CAM users. ${ }^{18}$ Participants reported public- and private-sector CAM provision in both rural and urban settings, and sought treatment from a range of CAM practitioners with and without medical training; many also had experience of other CAM therapies.

\section{Comparison with existing literature}

There has been no direct research into how individuals use CAM and $\mathrm{OM}$ in relation to each other, but specific elements of the study model are supported by other research. First, the participants in this study reported their use and experience of using multiple CAM therapies alongside OM; other studies, as reported below, investigating CAM/OM use likewise report participants' use of multiple CAM therapies, and thus comparison between trials is relevant. Using CAM to control OM side-effects and hence facilitate ongoing $\mathrm{OM}$ use has been described in patients receiving chemotherapy for cancer, ${ }^{28}$ and HIV. $^{29}$ Other studies have documented commonly held beliefs about the curative nature of CAM, ${ }^{10,30}$ and the role of $\mathrm{OM}$ in symptom relief. ${ }^{31,32}$ In the present study, some participants were also unexpectedly able to reduce their OM use when they perceived they no longer needed it. This welcome outcome helped them cope better with managing their illness; increased coping ability has previously been reported in the literature. ${ }^{29,33}$ Additionally, some participants reported beliefs that $\mathrm{OM}$ is orientated towards symptom relief.

Using CAM to reduce, avoid, and replace OM represents a continuum of decreasing OM use ranging from integrating $\mathrm{CAM} / \mathrm{OM}$ as equally important elements of self-care, to prioritising CAM as the primary treatment. This shifting pattern of participants' beliefs was based on their positive CAM experiences, ${ }^{6,7}$ their perception of failure of $\mathrm{OM}^{8,34}$ and adverse $\mathrm{OM}$ drug reactions. .,10,35-37 $^{\text {Participants }}$ universally continued their OM use for other health problems. ${ }^{7}$ The selection of CAM over OM did not reflect an ideological opposition to $\mathrm{OM},{ }^{26}$ but suggests people manage their health by selecting and integrating elements of CAM/OM for their specific needs. This is consistent with the study of Vincent et al, ${ }^{5}$ who suggested that while failure of OM may be a strong motive for initially seeking CAM, positive experiences of CAM become more important for subsequent treatment decisions. At the extreme of this continuum, using CAM to replace OM appears to be straightforward as it involves minimal negotiation between the two systems. It is particularly important to encourage such patients to disclose CAM use to OM practitioners, and vice versa, both to ensure safety and to allow the development of an informed and rational integrated treatment programme.
'Returning to OM' is important, and has received little attention in the literature. It reminds us that patients continue to reflect on and evaluate their therapeutic experiences and almost never commit to a single treatment modality for life when they have chronic illness.

\section{Implications for future research and clinical practice}

The study model provides the foundations to build both a research and clinical strategy in relation to integrated health care in chronic illness. ${ }^{38}$ Given the changeable nature of patients' decisions about their self-management, an ongoing and patient-centred dialogue between CAM and OM practitioners and patients is essential. Patients are often reluctant to disclose their CAM use, ${ }^{39}$ and doctors equally do not initiate these discussions with their patients..$^{40-42}$ GPs may therefore have a unique opportunity to influence and guide their patient's self-management, as doctors' views about CAM appear to be important to patients. ${ }^{43,44}$ The present study model suggests that much CAM use results from either a perceived lack of effective OM or concerns about its adverse effects. Conversations with patients about both their CAM and OM use would be advantageous, allowing alterations of orthodox treatment regimes or use of CAM to support and sustain them. Clinicians are concerned about patients rejecting $\mathrm{OM}$, but these findings confirm that although these participants may not have used OM for a particular condition, none totally abandoned OM. The authors believe their model offers valuable insight for both clinicians and researchers who want to understand how their patients integrate CAM and OM to manage their chronic illness. It opens up the possibility of an integrated, individualised, and constructive patient self-management strategy.

\section{Funding body}

Sarah B Brien was funded by a National Institute of Health Postdoctoral fellowship [PDA04/CAMs2/02]. During this work, Felicity L Bishop was initially funded by a grant from the Southampton Complementary Medical Research Trust and subsequently by a Career Development Fellowship from the Arthritis Research Campaign. George Lewith's post is partially funded by the Rufford Maurice Laing Foundation. Kirsty Riggs, David Stevenson, and Victoria Freire received no source of funding for this study.

\section{Ethical approval}

Ethical approval was received from University of Southampton School of Medicine Ethics Committee (SOMSEC003.07).

\section{Competing interests}

The authors have stated that there are none.

\section{Acknowledgements}

The authors would like to thank the patients who took part in this study and the practitioners and staff who assisted recruitment.

\section{Discuss this article}

Contribute and read comments about this article on the Discussion Forum: http://www.rcgp.org.uk/bjgp-discuss 


\section{REFERENCES}

1. Rao JK, Mihaliak K, Kroenke K, et al. Use of complementary therapies for arthritis among patients of rheumatologists. Ann Intern Med 1999; 131(6): 409-416.

2. Kong $\mathrm{S}$, Hurlstone $\mathrm{D}$, Pocock $\mathrm{C}$, et al. The Incidence of self-prescribed oral complementary and alternative medicine use by patients with gastrointestinal diseases. J Clin Gastroenterol 2005; 39(2): 138-141.

3. Vincent C, Furnham A. Why do patients turn to complementary medicine? An empirical study. Br J Clin Psychol 1996; 35(1): 37-48.

4. Cassileth BR, Lusk EJ, Strouse TB, Bodenheimer BJ. Contemporary unorthodox treatments in cancer medicine: A study of patients, treatments, and practitioners. Ann Intern Med 1984; 101(1): 105-112.

5. Vincent C, Furnham A, Willsmore M. The perceived efficacy of complementary and orthodox medicine in complementary and general practice patients. Health Educ Res 1995; 10(4): 395-405.

6. Ernst E, White A. The BBC survey of complementary medicine use in the UK. Complement Ther Med 2000; 8(1):32-36.

7. Kelner M, Wellman B. Health care and consumer choice: medical and alternative therapies. Soc Sci Med 1997; 45(2): 203-212.

8. Astin JA. Why patients use alternative medicine: results of a national study. JAMA 1998; 279(19): 1548-1553.

9. Vincent C, Furnham A. Complementary medicine: state of the evidence. J R Soc Med 1999; 92(4): 170-177.

10. Murray RH, Rubel AJ. Physicians and healers - unwitting partners in healthcare. N Engl J Med 1992; 326(1): 61-64.

11. Eisenberg DM, Kessler RC, Van Rompay MI, et al. Perceptions about complementary therapies relative to conventional therapies among adults who use both: results from a national survey. Ann Intern Med 2001; 135(5): 344-351.

12. Bishop FL, Yardley L, Lewith GT. Treat or treatment: a qualitative study conceptualising patients' use of complementary and alternative medicine. Am J Public Health 2008; 98(9): 1700-1705.

13. Jernewall N, Zea MC, Reisen CA, Poppen PJ. Complementary and alternative medicine and adherence to care among HIV-positive Latino gay and bisexual men. AIDS Care 2005; 17(5): 601-609.

14. Matthees BJ, Anantachoti P, Kreitzer MJ, et al. Use of complementary therapies, adherence, and quality of life in lung transplant recipients. Heart Lung 2001; 30(4): 258-268.

15. Manfredi R, Chiodo F. The effects of alternative treatments for HIV disease on recommended pharmacological regimens. Int J Antimicrob Agents 2001; 13(4): 281-285.

16. Kline-Rogers EM, Lingman P, Sharma S, et al. Adherence with traditional medication and complementary and alternative medicine use six months after hospital discharge in patients with acute coronary syndromes. J Am Coll Cardiol 2002; 39(S2): 444.

17. Feldman DE, Duffy C, De Civita M, et al. Factors associated with the use of complementary and alternative medicine in juvenile idiopathic arthritis. Arthritis Rheum 2004; 51(4): 527-532.

18. Thomas KJ, Nicholl JP, Coleman P. Use and expenditure on complementary medicine in England: a population based survey. Complement Ther Med 2001; 9(1): 2-11.

19. Fugh-Berman A, Ernst E. Herb-drug interactions: review and assessment of report reliability. Br J Clin Pharm 2001; 52 (5): 587-595.

20. Robinson A, McGrail MR. Disclosure of CAM use to medical practitioners: a review of qualitative and quantitative studies. Complement Ther Med 2004; 12(2-3): 90-98.

21. National Centre for Complementary and Alternative Medicine. What is complemetary alternative medicine. http:// nccam.nih.gov/health/whatiscam/ (accessed 15 Jun 2010).

22. Ritchie J, Spencer E. Qualitative data analysis for applied policy research. In: Bryman A, Burgess RG (eds). Analyzing qualitative data. London: Routledge, 1994; 173-194.
23. Balneaves LG, Long B. An embedded decisional model of stress and coping: implications for exploring treatment decision making by women with breast cancer. J Adv Nurs 1999; 30(6): 1321-1331.

24. Boon H, Brown JB, Gavin A, Westlake K. Men with prostate cancer: making decisions about complementary/alternative medicine. Med Decis Making 2003; 23(6): 471-479.

25. Yates PM, Beadle G, Clavarino A, et al. Patients with terminal cancer who use alternative therapies: their beliefs and practices. Sociol Health Illn 1993; 15(2): 199-216.

26. Thorne S, Paterson B, Russell C, Schultz A. Complementary/ alternative medicine in chronic illness as informed self-care decision making. Int J Nurs Stud 2002; 39(7): 671-683.

27. Truant T, Bottorff JL. Decision making related to complementary therapies: a process of regaining control. Patient Educ Couns 1999; 38(2): 131-142.

28. Boon H, Brown JB, Gavin A, et al. Breast cancer survivors' perceptions of complementary/alternative medicine (CAM): making the decision to use or not to use. Qual Health Res 1999; 9(5): 639-653.

29. Pawluch D, Cain R, Gillett J. Lay constructions of HIV and complementary therapy use. Soc Sci Med 2000; 51(2): 251-264.

30. Singh H, Maskarinec G, Shumay DM. Understanding the motivation for conventional and complementary/alternative medicine use among men with prostate cancer. Int Cancer Ther 2005; 4(2): 187-194.

31. Britten N. Patients' ideas about medicines: a qualitative study in a general practice population. Br J Gen Pract 1994; 44(387): 465-468.

32. Caspi O, Koithan M, Criddle MW. Alternative medicine or 'alternative' patients: a qualitative study of patient-oriented decision-making processes with respect to complementary and alternative medicine. Med Decis Making 2004; 24(1): 64-79.

33. Thomas KJ, MacPherson H, Ratcliffe J, et al. Longer term clinical and economic benefits of offering acupuncture care to patients with chronic low back pain. Health Technol Assess 2005; 9(32): 1-109.

34. Moore AD, Petri MA, Manzi S, et al. The use of alternative medical therapies in patients with systemic lupus erythematous. Arthritis Rheum 2000; 43(6): 1410-1418.

35. Zollman C, Vickers A. ABC of complementary medicine: users and practitioners of complementary medicine. BMJ 1999; 319(7213): 836-838

36. Furnham A, Smith C. Choosing alternative medicine: a comparison of the beliefs of patients visiting a general practitioner and a homeopath. Soc Sci Med 1988; 26(7): 685-689.

37. Bishop FL, Yardley L, Lewith GT. A systematic review of beliefs involved in the use of complementary and alternative medicine. $J$ Health Psychol 2007; 12(6): 851-867.

38. MacPherson H, Peters D, Zollman C. Editorials. Closing the evidence gap in integrative medicine. BMJ 2009; 339: b3335.

39. Robinson A, McGrail MR. Disclosure of CAM use to medical practitioners: a review of qualitative and quantitative studies. Complement Ther Med 2004; 12(2-3): 90-98.

40. Perry R, Dowrick C. Complementary medicine and general practice: and urban perspective. Complement Ther Med 2000; 8(2): 71-75.

41. Shelley B, Sussman A, Williams R, et al. They don't ask me so I don't tell them': patient-clinician communication about traditional, complementary, and alternative medicine. Ann Fam Med 2009; 7(2): 139-147.

42. Wharton R, Lewith G. Complementary medicine and the general practitioner. Br Med J (Clin Res Ed) 1986; 292(6534): 1498-1500.

43. Lewith GT, Hyland M, Gray SF. Attitudes to and use of complementary medicine among physicians in the United Kingdom. Complement Ther Med 2001; 9(3): 167-172.

44. Lewis D, Paterson M, Beckerman S, Sandilands C. Attitudes towards integration of complementary and alternative medicine with hospitalbased care. J Complement Altern Med 2001; 7(6): 681-688. 